\title{
VIEWS AND GOALS OF KARAITE-KARAIM STUDIES*
}

\author{
TAPANI HARVIAINEN \\ Department of World Cultures, University of Helsinki \\ FI-00014 Helsinki, P.O. Box 59 (Unioninkatu 38 B), Finland \\ e-mail: tapani.harviainen@helsinki.fi
}

This paper, a version of the introductory lecture read at the Szeged Workshop on Karaim Studies, is intended to present various themes and materials in the field of Karaite-Karaim-Hebrew studies that can be considered as waiting for more developed instruction, deeper observation or revised examination, and/or to offer promising new topics of research. The importance of private archives is referred to and similarly the need for careful preservation of material collections, recordings, manuscripts, etc. In addition to research, the Karaim culture also deserves support on the part of scholars.

Key words: merger of Hebrew and Karaim languages, collections of Karaim cultural heritage, public and private archives, mini history, promotion of Karaim culture.

At the start of our Szeged Workshop on Karaim Studies I had the honour and pleasure of expressing my own deep gratitude and - I believe - that of all the participants in this Workshop to the University of Szeged for this pleasant opportunity to come together in Hungary to deal with Karaim studies, the magnet that attracts, draws and unites us from numerous different perspectives and viewpoints. Simultaneously I wish to extend our gratitude to Uppsala University and Professor Éva Csató Johanson for the great support of our workshop. And, in particular, we are very grateful to Dr. Zsuzsanna Olach who has also been responsible for all the practical - physical and mental - and intellectual arrangements in favour of our academic and social welfare in Szeged and at its University. With this publication of my paper I wish to repeat our warm feelings of gratitude.

\footnotetext{
* Introductory address at the Szeged Workshop on Karaim Studies, June 13th, 2014.
} 
This presentation endeavours to introduce a number of ideas of the present state and future of Karaite and Karaim studies. As a continuation, I hope, we can intensify the search for themes that may offer fresh subjects for young scholars and the co-operation between them in these days and hereafter.

In various contexts I have said that my wake-up call into Karaim studies took place in The Hague in September 1977 when I saw the book Karaims in Poland by Ananiasz Zająckowski in the showcase of an antique shop. Next morning I entered the shop and bought the book and realised that Karaims were still alive. Before that time I had learned in my studies of Semitics that Karaites were a mediaeval reform movement of Judaism in the Middle East - without a mention of their later phases. During the past 37 years since 1977, the number of publications dealing with Karaites and Karaims has been increasing radically. In fact, it is no exaggeration to say that during those decades Karaite and Karaim studies have turned into one of the fashionable topics of Semitic studies, Turkology, and religious studies. The search for fresh themes, the opening of new archives, and a growing interest towards various minorities can be enumerated as factors behind this research revival. At present, we have massive handbooks, multiform specialised studies of history, linguistics, philology, and ethnology; journals, collections of articles, electronic study materials, home pages, mass media programmes, etc. at our disposal. Thus I believe that the existence of the Karaites and Karaims of today is no great surprise to young scholars in the field of humanities, as it was in my case in The Hague. One may argue about the quality, reliability, and tendencies of various books or TV programmes, but less about the availability of information on the past and present of Karaites-Karaims, either at a general level or at numerous more profound ones.

Though we can be satisfied with this change and trend - and even with our role in the process - we, nevertheless, have no reason for being afraid that everything in the field has been completed. Without being exhaustive I will try to describe themes that in my opinion constitute gaps and desiderata and are awaiting action.

One of the well-known obstacles in Karaite-Karaim studies is the merger of the Hebrew and Karaim languages in literary works, in particular, plus the great number of other European and non-European languages fluently employed by various groups of Karaites-Karaims in various centuries. Leaving aside here the problems of familiarity with Turkish, Arabic, Polish, Ukrainian, Lithuanian, etc., I stress the importance of learning both Hebrew and Karaim in case we have students who wish to concentrate on the topics we here are interested in. I believe that in our field there are rather few themes in which we have not missed more advanced knowledge of either Karaim and Turkic or Hebrew in their various phases - depending on the direction from which we have entered the numerous branches of our preoccupation.

Academic institutions where both Hebrew and Karaim are taught are extremely few in number. And as a rule the Hebrew that is available is either biblical or modern Hebrew, while mediaeval Hebrew would offer the sort of "Holy Tongue" that is most productive in terms of Karaite-Karaim studies. We scarcely can change this situation during the prevalent trends of academic policy and the economy ruling them. 
At present, however, we fortunately have the Internet course Syllabus for Karaim prepared and published by Prof. Éva Csató at Uppsala University. Next to it a parallel course of Karaite-Karaim Hebrew on the Internet or in a traditional book form would be very welcome. It could be based on a systematic collection of texts that contain Hebrew prose and poetry written by Karaite chakhamim in the 17th-19th centuries - during which Hebrew was a vital part of good education - their linguistic analysis and commentaries. Of course, this kind of course would demand preliminary studies of biblical or/and modern Hebrew; nevertheless, it would offer a tool which for the time being is out of our reach. The compilation of this kind of course demands substantial work, I admit, but perhaps an initiative may become fruitful on an auspicious day.

As a theme which invites me to penetrate more deeply, I would like to mention the early grammar books of Hebrew that quite a number of Karaim scholars are said to have composed in Eastern Europe from the 16th century onwards. The booklets were printed only occasionally and they are not easily detected in libraries, to say nothing of the diqduqim that remained in manuscript form. But perhaps a younger Hebraist - hopefully knowing Karaim, too, - will discover them in the years to come. With respect to earlier grammarians, one of the interesting aspects awaiting clarification is the entry of the grammatical theory established by the rabbanim in Spain in the 10th century among the Karaite-Karaim scholars, too; this process resulted in the replacement of the ancient Karaite grammatical tradition by the new rabbanite doctrine.

If Hebrew is discussed further, a Karaim-Hebrew dictionary is hardly necessary, and I cannot see an ordinary Hebrew-Karaim dictionary to be a must, either. However, the importance of the Bible translations into the Karaim language has become increasingly evident thanks to the recent research conducted by several scholars. In addition to rich linguistic materials, the translations offer a unique source of Karaite-Karaim exegetical traditions. And, in particular, I refer to their contribution to the comparative study of translation techniques. The ideal of a literal word-to-word translation is often considered as being characteristic of Karaite-Karaim renderings of biblical texts, and a number of girsa-peshat lists of word-for-word transformations have been published independently or as appendices in biblical monographs. In my opinion, it would be feasible, useful, and instructive to strive to compile an extensive Hebrew-Karaim girsa-peshat dictionary or an electronic database of the exegetical and translational studies.

Still about Hebrew: many students are woefully aware of the jungle that the boundless abbreviations present to the dismay of the poor reader. There are numerous dictionaries of Hebrew abbreviations based on the rabbinic literature, grave monuments, documents, etc. that can be used in Karaite-Karaim research, too. However, the Karaite-Karaim writers and scribes had their own customs and habits which resurface in manuscripts, books, and documents. These abbreviations should also be collected and provided with resolutions and various optional interpretations, all of them derived from actual occurrences and contexts. For this purpose an electronic database 
would be preferable initially, at least, since it could be updated in the face of new findings and amendments.

Moving from Hebrew in the direction of other Karaite-Karaim languages, I would like to arrive at archives irrespective of their particular contents. I presume that the official archives and collections are rather well known. Nevertheless, for example the destinies of the collections of the Karaim Bitikligi library in Eupatoria are unclear, Harkavy's catalogue of the Firkovich Collections in St. Petersburg is still a myth, and the holdings of the Firkovich collections in both St. Petersburg and Vilnius contain hundreds of memorial qina poems in Hebrew and Karaim that could be investigated as rich materials for e.g. the personal history - just to mention only some lines of future research to be conducted in the well-known libraries.

On the borderline between public and private materials there are numerous branches of Turkic and Karaim linguistic and philological research. The development of various Karaim dialects has recently received considerable new light on the basis of the meticulous scrutiny of private letters and madjumas, and similarly the studies of Bible translations into Karaim dialects and paraliturgical poetry in Hebrew and Karaim have followed the true traditions of text studies enriched with modern viewpoints and conclusions. The recordings of the living Karaim vernaculars and their analysis carried out by Éva Csató and her colleagues also represent invaluable trends of Karaim linguistics, and the Karaim pronunciation tradition of biblical Hebrew has thus been recorded before its extinction. I am convinced that the linguists can detect a great number of promising future projects and materials that still wait for them to make productive selections among the most attractive subjects.

Furthermore, a few words about the private collections and libraries that concentrate on Karaite-Karaim materials. Several young scholars among us have exciting experiences of the various personal gems and invaluable source materials that the private archives conceal - waiting for researchers who have respect for them and their possessors, the expertise for evaluating them, and the abilities of making use of them in a proper way. It is well known that special talents are needed for satisfying the expectations of the owners and their sentiments, while simultaneously the audience of the future publications may look forward to reading the exposure of intriguing hidden secrets.

As a concrete example I refer to the letters kept in the personal archives that have enabled Dr. Michał Németh in recent years to uncover remarkable new views of the phonetics and phonology in the south-western Karaim spoken a century ago in Łuck and Halicz, and additional discoveries and dates for the changes of pronunciation are to be anticipated.

In this context the so-called mini history projects are worth mentioning: a story of a family or an event in a village or a luckless cultural attempt can expose their time periods and cultural frameworks in an exceptionally piquant, fashionable, and attractive light.

In this regard I presume that a great number of the short reports, interviews, and recollections published in the journal Awazymyz in Polish over many years would be appreciated by an extensive readership when offered, from time to time, as a supple- 
ment in English, German or French. Thanks to our Polish colleagues we have received publications of old photos lately which bring to life the past of Karaim settlements during the last two centuries. An exhibition and/or album in English and/or German based on these pictures would also arouse lively interest outside Poland and Lithuania.

Genealogy and personal history have become a fashionable hobby and they have profited various branches of the research of history. In the case of Karaims, numerous articles published in the Awazymyz could also benefit these aspirations. On a more comprehensive scale, a thoroughly revised version of Boris El'yashevich's biography and bibliography (Народы и культуры, XIV, Moscow 1993) focused on Karaims in Europe would fulfil a really welcome desideratum.

The extensive archives of Karaim music collected in Lithuania originally consist of private recordings; a renewed scrutiny of them may offer new horizons for the origins of the Karaite-Karaim recitation of biblical texts. The collections could perhaps be expanded to the vestiges of the genres that are in danger of falling into oblivion, and the traces of Crimean Karaim music traditions could be included in the collections - as far as the situation in the Crimea allows this kind of activity.

After these suggestions I admit without any hesitation that the list is by no means exhaustive. In contrast, it is plausible that many other archives, material collections, and new themes will surface to be used to the satisfaction of the collectors and the positive increase of knowledge.

The complement of preserving and researching - the public and private - archives consists of the creation of new archives. Herewith I refer to the very multiform collections of Karaite-Karaim materials that scholars or amateurs have acquired or produced in the format of recordings, photo copies, photos, digital images, etc. or which they are collecting even now. I do hope that these kinds of collections have entered or will enter into secure havens where they will be preserved permanently. However, I am afraid that many among the owners must admit to the questionable situation that the collections still stay at home. And as for those who have displayed concern about the archives some collections or their copies are located at the moment, I dare guess that they exist in widely dispersed archival institutions or data banks of universities or their various departments. Well and good, if the treasures are safe.

However, is it an idle dream that at some time there could exist a Central Archive of Karaim Recordings? I am not too unrealistic to imagine a huge museum of all the manuscripts, books, prints and recordings; I can outline an archive where the scholars and collectors could deposit the Karaite-Karaim items that they have acquired or compiled and that can be considered worth retaining and utilising in the future. Original objects and their various copies would be welcome; copies are easily produced nowadays. Where should the Central Archive of Karaim Recordings be established? I suggest a university city with vital connections with Karaims, Karaim studies and publishing activities. Poznań, Vilnius, Uppsala, Cracow, ... - a tough competition could be opened right now! Just one small detail - who is going to finance and/or sponsor the Archive? 
It is excellent that the journal Karaite Archives has been launched by the Adam Mickiewicz University in Poznań. I believe that this journal specialised in KaraiteKaraim studies can grow into an important international organ of publications, bibliographical information, and communication of people focusing on Karaite-Karaim activities. As a forum for our publications there are also other journals at our disposal; however, the traditional periodicals of the type Studia NN or Acta XYZ are used to serve all of Asia and Africa. In contrast, Karaite Archives can be hoped to develop into the journal that because of its concentration is downloaded and recognised as number one in the field of Karaite-Karaim studies. The conferences planned to take place on the basis of the initiatives of Adam Mickiewicz University are also highly appreciated.

Numerous electronic home pages offer their services to a person searching for information about Karaites-Karaims. However, the pages are widely disparate in their quality, but in the free world no supervisor can be responsible for their universal reliability. What is annoying even in the best of them is the continued existence of outdated material that should be cleared from time to time.

So far I have referred to numerous targets of research and recordings of KaraiteKaraim traditions, topics which scholars used to appreciate. However, one most essential theme and object, at least, still awaits discussion. As scholars we should also be concerned about the future and maintenance of the Karaim culture. It is not sufficient to be satisfied with collecting, recording, and examining the materials of a culture, while the survival and development of this culture is endangered.

It is really a great achievement that the eleven Karaim Language Summer Schools have convened hundreds of participants to different levels of Karaim language courses, cultural lectures, dancing, and the theatre plays of the final celebrations. In addition to studies and learning, these schools have made an invaluable contribution to the mutual feeling of working together, public visibility and pride, in other words, positive elements of identity. In these attempts the input of Prof. Éva Csato together with the Karaim cultural associations has had the central role. For this purpose she has been able to raise money from several Swedish institutions and Uppsala University, to create the general plan of the Summer Schools, to pinpoint capable teachers, and to play with great success in numerous theatre roles as well. And what is most important, the Summer Schools were not a lucky event once in a beautiful summer, but have become a permanent tradition; thus their effect is multiple and deeply impressive.

In the same spirit, we can keep in mind the numerous liturgical books, textbooks, phrase books, dictionaries, and CDs which have appeared during the last 25 years to support the learning of Karaim language and its revival. The Summer Schools and publication activities can be considered to represent the most crucial objectives to be promoted in the upcoming years.

What else could be done to boost the prospering of the Karaim language in our days and thereafter? Do the so-called "language nests" constitute a path that could be materialised? Actually these nests imply kindergartens in which grandparents would tend grandchildren speaking together only the language to be revived. Despite the fact that the parents of children have forgotten Karaim in our case, in such a nest 
the children would learn the language of their grandparents - according to the natural method.

I hope I have been able to display here some views and goals, some of which can be discussed later on, others perhaps recalled in another situation, and the rest forgotten after this moment. 